\section{¿Puede la exposición al tráfico provocar el infarto del miocardio?}

En algunos estudios se propone que la enfermedad cardiovascular puede agravarse por exposición al tráfico vehicular. En zonas urbanas, la cantidad de tráfico se considera un posible factor de riesgo de esa enfermedad. Un estudio de cohortes indicó que el riesgo de muerte por causas cardiorrespiratorias es dos veces más alto en personas que viven cerca de una carretera principal. Además, estudios de casos y controles muestran que el ambiente de trabajo de los conductores profesionales puede contribuir al riesgo de infarto del miocardio. Varios investigadores alemanes decidieron formarse un juicio al respecto mediante un estudio para determinar si el tráfico puede provocar el infarto del miocardio, que es una de las causas de muerte más comunes por enfermedad cardiovascular. Se inicia súbitamente y se relaciona con factores del estilo de vida como el ejercicio vigoroso, la ira y el consumo de cocaína y marihuana. La presencia en el ambiente de partículas de contaminantes sólidas es otro posible factor de riesgo.

Con datos obtenidos de la Investigación en Salud Cooperativa del Registro de Infartos de Miocardio de la Región de Augsburgo, el grupo de investigadores realizó un estudio cruzado de casos con pacientes que habían sufrido infarto del miocardio durante el período de febrero de 1999 hasta julio de 2001. En el Registro se incluyen de ordinario sobrevivientes de infarto del miocardio hospitalizados que tienen de 25 a 74 años de edad. Se seleccionaron 691 historias clínicas en las que se especificaba la fecha y hora del infarto en personas que habían sobrevivido por lo menos 24 horas después del suceso y que proporcionaban información sobre los factores que podrían haber provocado el infarto. Se entrevistó a los participantes en el hospital lo más pronto posible después de su llegada y se tomaron datos sociodemográficos, historias clínicas e información sobre el hábito de fumar. Se mantuvo también un diario de estudio, en el que se recolectaron datos sobre las actividades de los pacientes en los cuatro días anteriores a los síntomas: horas de sueño y de actividad durante el día, tiempo al aire libre, forma de transporte, localidad, presencia o ausencia de angina de pecho, fuerte ira o alegría y cualquier exposición a polvo o disolventes. Los pacientes eran predominantemente varones y $70 \%$ tenían 55 o más años de edad. La mayoría había experimentado solo un infarto del miocardio y casi todos sobrevivieron hasta 28 días. Para evaluar la asociación entre la exposición esporádica a varias intensidades de tráfico y el inicio del infarto del miocardio, se usaron modelos de regresión logística condicional.

Los resultados mostraron una asociación entre la exposición al tráfico y un infarto dentro de la hora siguiente (razón de posibilidades $=2,92$; IC95\%: 2,22-3,83; $P<0,001$ ). La exposición fue más frecuente en el mismo día del infarto que en los tres días anteriores. Ese día, de todas las horas que los pacientes estuvieron expuestos al tráfico, $72 \%$ las pasaron en automóvil, $16 \%$ en bicicleta, $10 \%$ en medios de transporte público y $2 \%$ en motocicletas. Los porcentajes de horas de exposición fueron similares en los tres días previos. La cantidad de tiempo que los sujetos pasaron en automóviles, transporte público, motocicletas o bicicletas correspondió directamente al grado de riesgo de infarto del miocardio. Una hora antes de que comenzaran los síntomas, la exposición al tráfico había sido el doble que en cualquier otro momento.

La exposición al tráfico pareció asociarse a un riesgo mayor en las mujeres y en los pacientes de 60 años o más. Las estimaciones de efectos fueron más altas en diabéticos y personas sin trabajo, pero solo el estado de empleo modificó de forma significativa la asociación entre el riesgo de infarto del miocardio y la exposición al tráfico. La frecuencia de exposición fue diferente según la hora del día (mañana, $8,3 \%$; tarde, $7,1 \%$; noche, $0,9 \% ; P<0,001)$ y el día de la semana (lunes, $6,0 \%$; martes, $5,8 \%$; miércoles, $5,7 \%$; jueves, $4,7 \%$; viernes, $5,7 \%$; sábado, $4,4 \%$, y domingo, 2,9\%; $P<0,001)$.

El empleo de un automóvil fue la causa más corriente de exposición al tráfico, pero también se observó una asociación entre el tiempo pasado en transporte público y el infarto en la hora siguiente. El estudio cruzado de casos permitió evaluar factores de riesgo pasajeros que pueden provocar el infarto del miocardio en personas susceptibles. Esos factores tienen un efecto en el corto plazo y fueron el ejercicio vigoroso, la ira y el consumo de cocaína o marihuana. Los factores de riesgo crónicos, como el hábito de fumar, la dislipidemia y la vida sedentaria, tienen efectos prolongados, conducen a la ateroesclerosis y a los procesos protrombóticos y pueden dar como resultado el deterioro del miocardio, así como predisponer a trastornos coronarios agudos. 
De los casos de infarto del miocardio incluidos en el estudio, $8 \%$ se pudieron atribuir a la exposición al tráfico. Es posible que a ello contribuyeran factores como el estrés, el ruido y la contaminación producida por el tráfico. La exposición crónica a esos estímulos es un factor de riesgo de enfermedad cardiovascular bien conocido que puede producir concentraciones elevadas de las hormonas que se secretan en situaciones de estrés. Además, se ha comprobado que el riesgo de muerte por cardiopatía isquémica aumenta en personas con ocupaciones que las exponen al tráfico, como los policías. Por otra parte, la contaminación ambiental con partículas sólidas puede estar asociada a aumentos temporales de la viscosidad plasmática, de reactantes de fase aguda y de trastornos endoteliales, así como a la alteración del control autónomo cardíaco. En fin, con los conocimientos actuales, es imposible determinar el aporte relativo de distintos factores como el estrés y la contaminación al infarto del miocardio. No obstante, los esfuerzos que se están haciendo en los centros urbanos para conseguir un ambiente más limpio y sano y automóviles que produzcan menos contaminantes seguramente beneficiarán a las personas en riesgo de sufrir enfermedades cardiovasculares. (Peters A, et al. Exposure to traffic and the onset of myocardial infarction. N Engl J Med. 2004;351:1721-1730.)

\section{Se mide el punto en que fracasan tres clases de antirretrovíricos}

Una de las metas del tratamiento antirretrovírico de gran actividad (TARGA) es reducir la viremia a niveles indetectables para reducir las posibilidades de evolución del virus como respuesta a las presiones de selección terapéutica. Después de una buena respuesta inicial a ese tratamiento, en algunos pacientes la carga vírica rebota, lo que puede provocar la aparición de virus resistentes a los medicamentos y plantear dificultades para el cumplimiento del régimen a largo plazo. Esos pacientes se suelen cambiar a regímenes de segunda línea o "de rescate", a los cuales la respuesta es por lo general menos satisfactoria que al tratamiento inicial. Los tratamientos de rescate a menudo consisten en otra clase de antirretrovírico, de modo que un TARGA con un inhibidor de las proteasas puede sustituirse por un inhibidor de la transcriptasa inversa no nucleosídico o lo contrario. Una vez que los pacientes experimentan fracaso virológico con las tres clases principales de antirretrovíricos, las opciones son muy limitadas debido a la resistencia cruzada. En esos pacientes es difícil mantener la carga vírica lo suficientemente baja, así que la concentración de linfocitos CD4 disminuye y la enfermedad pro- gresa. Se cuenta con bastante información sobre la respuesta a los TARGA de primera y segunda línea, gracias a un buen número de estudios de observación y ensayos clínicos. Sin embargo, se sabe poco en cuanto al tiempo que dura el TARGA antes de fracasar y la prevalencia e incidencia de los fracasos.

Teniendo en cuenta esas cuestiones, se hizo una investigación de 3496 pacientes con infección por VIH-1 que habían participado en el estudio prospectivo Eurosida, llevado a cabo en 72 centros de Europa, Israel y Argentina. Los centros proporcionaron datos sobre los pacientes ambulatorios atendidos consecutivamente a partir del 2 de mayo de 1994 hasta que se consiguió un número determinado de pacientes de cada centro. Después de esa primera cohorte de 3115 pacientes denominada Eurosida I, ingresaron en el estudio cuatro cohortes más: Eurosida II, comenzada en diciembre de 1995 (1 365 pacientes); Eurosida III, abril de 1997 (2 839 pacientes); Eurosida IV, abril de 1999 (1 225 pacientes); y Eurosida V, septiembre de 2001 (1 258 pacientes). Al inicio, se obtuvieron de cada participante datos demográficos y clínicos, los cuatro recuentos más recientes de linfocitos $\mathrm{CD} 4$ y mediciones de la carga vírica. En cada visita de seguimiento se revisaban esos datos y se anotaban las fechas del comienzo y fin de cada tratamiento antirretrovírico, así como información sobre el uso de medicamentos profilácticos contra infecciones oportunistas. El último seguimiento tuvo lugar en diciembre de 2003.

El TARGA se definió como la combinación de un mínimo de tres antirretrovíricos; por lo menos uno tenía que ser un inhibidor de las proteasas, un inhibidor de la transcriptasa inversa no nucleosídico o abacavir. Todos los pacientes que iban a recibir el TARGA por primera vez eran idóneos para el estudio. Se excluyó a todo paciente tratado anteriormente con un inhibidor de la proteasa o un inhibidor de la transcriptasa inversa no nucleosídico que no fuera parte de un TARGA. La fecha en que se empezó el TARGA quedó registrada como punto de partida. Los pacientes que habían recibido TARGA antes de ingresar a Eurosida se podían incluir solo si se les había medido la viremia dos veces al año en esa época anterior. Se conseguía así que no hubieran ya tenido un fracaso terapéutico con el tratamiento triple.

Se consideró que había fracaso virológico con cualquier clase de antirretrovírico cuando todas las mediciones de viremia registradas daban $>1000$ copias de ARN del VIH por mL de plasma después de 4 meses o más de tratamiento. También se consideraba fracaso de cualquier clase de antirretrovírico si, al administrarse una monoterapia, un tratamiento con dos o tres medicamentos u otro aun más intensivo, la viremia era de $>1000$ copias $/ \mathrm{mL}$ por 